\section{onil}

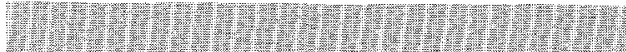

OAK RIDGE NATIONAL LABORATORY
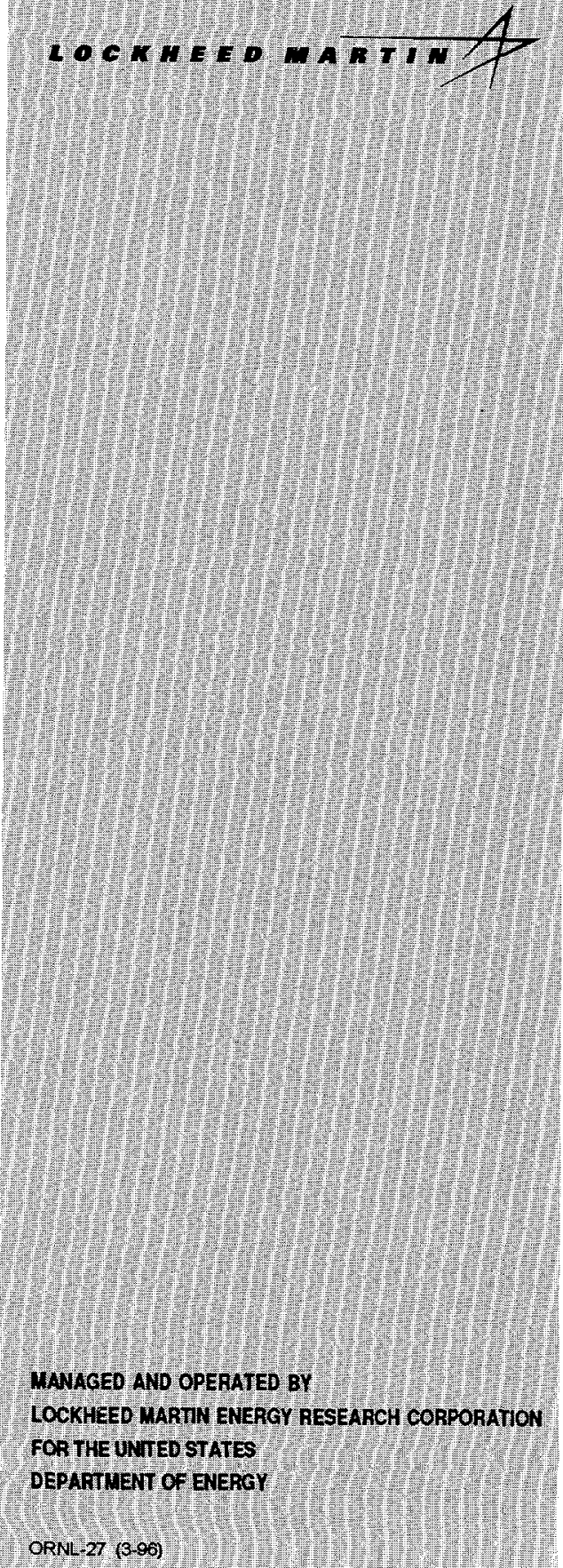

CRADA Final Report for CRADA Number ORNL94-0256

\section{A Low-Waste Electrospray Method for Applying Chemicals and Finishing Agents to Textiles}

\author{
X. (Shaw) Zhang \\ (Principal Investigator) \\ Oak Ridge National Laboratory \\ D. A. Alexander \\ (Principal Investigator) \\ AMTEX Partnership TReC Project \\ Prepared by the \\ Oak Ridge National Laboratory \\ Oak Ridge, Tennessee 37831 \\ managed by \\ Lockheed Martin Energy Research Corp. \\ for the \\ U.S. Department of Energy \\ under contract DE-AC-05-960R22464

\section{APPROVED FOR PUBLIC RELEASE: DISTRIBUTION IS UNLIMITED}

This work was supported through a CRADA with the AMTEX Partnership TReC Project, Spartanburg, South Carolina, sponsored by the Laboratory Technology Research Program Office, Office of Energy Research, U.S. Department of Energy, under contract DE-AC05-96OR22464 with Oak Ridge National Laboratory, managed by Lockheed Martin Energy Research Corporation. 


\section{DISCLAIMER}

This report was prepared as an account of work sponsored by an agency of the United States Government. Neither the United States Government nor any agency thereof, nor any of their employees, make any warranty, express or implied, or assumes any legal liability or responsibility for the accuracy, completeness, or usefulness of any information, apparatus, product, or process disclosed, or represents that its use would not infringe privately owned rights. Reference herein to any specific commercial product, process, or service by trade name, trademark, manufacturer, or otherwise does not necessarily constitute or imply its endorsement, recommendation, or favoring by the United States Government or any agency thereof. The views and opinions of authors expressed herein do not necessarily state or reflect those of the United States Government or any agency thereof. 


\section{DISCLAIMER}

Portions of this document may be illegible in electronic image products. Images are produced from the best available original document. 


\title{
A Low-Waste Electrospray Method for Applying Chemicals and Finishing Agents to Textiles
}

\author{
Final Report for CRADA ORNL94-0256
}

\author{
X. (Shaw) Zhang \\ Oak Ridge National Laboratory \\ Chemical Technology Division
}

\begin{abstract}
This electrospray technology works by applying the desired chemicals onto a substrate as electrically generated, charged sprays. By imposing a potential difference between the application nozzle and the target, it is possible to precisely direct and control the spray. This electrospray method of application gives a small droplet size and a relatively uniform size distribution, with the added advantage of an easily controllable spray angle. It potentially offers substantial improvement over traditional methods in the area of application uniformity, resulting in improved product quality. Additionally, since the chemicals are electrically directed straight onto the fiber with a minimum of overspray, the electrospray method holds promise in the area of waste reduction, resulting in lowered production cost.
\end{abstract}

\section{Statement of the Objectives}

The objective of this project was to investigate the feasibility of improved application of chemicals and finishing agents to fabrics and yarns using electrospraying techniques. The collaborative work was to involve lab-scale studies primarily at ORNL, followed by testing with working prototypes at industrial pilot sites.

\section{Technical Discussion of Work Performed}

Work performed in fiscal year 1995 concentrated on electrostatic spraying of chemicals and finishing agents onto fabrics, and that in fiscal year 1996.concentrated on the electrohydrodynamic stable cone-jet spraying of droplets directed onto thread.

Multi-nozzle units for electrospraying chemicals and finishing agents onto fabrics were constructed and tested for different operating conditions. Based on the studies of electrostatic and hydrodynamic interactions among the charged liquid jets and sprayed droplets, the configuration of the system (including distances between nozzles, the nozzle and its sleeve, and electrodes) was adjusted for optimizing the spray quality (droplet size, spray angle, uniformity, and fabric wet pickup). The spray uniformity on fabrics was measured for solutions of industrial interest by digital scanning analysis and estimated on-line by simple measurements of wet pick-up at different positions across the width of fabrics. Both measurements showed relatively uniform coverage of the finishing materials on fabrics. In addition, the sprayed droplet size, size distribution, and velocity were measured by a phase-Doppler anemometer, which allows accurate characterization of the spray quality and correlation of the operating parameters for optimal operations.

A lab-scale electrospray unit with a single nozzle for spraying onto yarns was also developed and constructed. Experiments with different charging configurations were conducted. It was determined that a configuration in which the nozzle is grounded and the backplate is charged is the best suited for electrospraying onto yarn, as it readily produces a stable cone-jet spray of fine droplets (drop radius $<20$ micrometers). This small drop size may result in a significant improvement over traditional liquid application methods. The grounded nozzle configuration is also advantageous in that any pump can be 
used without being insulated; the charged backplate is very easily insulated. Extensive and systematic experiments toward optimization of the quality and distribution of sprayed droplets of different liquids were carried out. Parameters investigated included liquid flow rate, viscosity, surface tension, and conductivity, as well as electric field strength and spray angle. Stable sprays were demonstrated with solutions over a 1-1500 $\mathrm{cP}$ viscosity range. Yarn path guides and a spin finish gear pump were provided by industry.

\section{Unique contribution of ORNL to this project}

ORNL was uniquely capable of contributing to this project since several years of research had been invested into the use of electric fields in oscillating, breaking and coalescing drops, and causing atomization. This lab has the electrospray equipment and instrumentation to obtain the necessary data, including a phase-Doppler anemometer for determining size distribution and velocities of aerosol droplets, and a high-speed image analyzer to study spray angles and the stability of liquid jets.

\section{Benefits to DOE and ORNL}

The work done on this CRADA was such that it improved our fundamental understanding of electrostatic spraying and deposition processes. The knowledge gained from this project can be adapted to phaseseparation processes and advanced materials synthesis, thereby supporting ORNL competencies in separations, materials synthesis, characterization, and processing. A specific example is the knowledge generated in the single-nozzle studies, which supported efforts in an Office of Basic Energy Sciences project on interface stabilization and fine-droplet generation.

\section{Inventions}

No inventions were reported and pursued during the course of this work.

\section{Plans for Future Collaboration}

There were plans for another phase of experiments with pilot-scale processes, along with technique commercialization in FY1997; however, funding was not extended.

\section{Conclusions}

Although the project was not extended to pilot-scale testing and implementation, this work provided a significant benefit to the industrial partners by illustrating the feasibility and benefits of an electrospray method for applying chemicals and finishing agents to textiles. The electrospray technology offers an excellent opportunity to commercialize a process that could lead to an enhanced uniformity of chemical application, with a resulting improvement in the quality of industrial products. In addition, the possibility for a reduction in the amount of excess chemicals used in processing could potentially reduce operating costs. 
INTERNAL DISTRIBUTION

1. D. W. DePaoli

2. A. J. Luffman

3. P. L. Gorman

4. R. T. Jubin
5. C. A. Valentine

6. X. Zhang

7-8. Laboratory Records

\section{EXTERNAL DISTRIBUTION}

9. D. A. Alexander, Director AMTEX Partnership TReC Project, 775 Spartan Blvd., Suite 203, Spartanburg, SC 29301.

10. P. S. Farber, Argonne National Laboratory, 9700 South Cass Ave., Argonne, IL 60439. 